\title{
Arduino Based Underground Cable Fault Detector
}

\author{
G.Sasidhar Achari, Mohana
}

\begin{abstract}
The objective of this errand is to choose the partition of the failure of the underground connection in the base station using one kilometer of Arduino board. Underground connection structure is a run of the mill practice in various urban zones. Notwithstanding whether a mistake occurs for no good reason, around then the fix methodology related to this particular connection is inconvenient because of not knowing the unmistakable zone of connection dissatisfaction. The assignment uses the praiseworthy thought of the Ohms law, when a low voltage close to the completion of the power supply device is associated over a course of action resistor the present changes depending upon the zone of the Fault the connection. By virtue of a short out (grounded line), the voltage over the course of action resistors changes as requirements be, by then commitment to the ADC fabricates the Arduino board to make exact modernized data for the in kilometer. The endeavor is mounted with an impediment addressing the length of the connection in $K M$ and making absconds is executed by a ton of switches in each acknowledged KM to check its precision. Dissatisfaction occurs at a given partition and the specific stage is appeared on a LCD screen related with the Arduino board.
\end{abstract}

Keywords: Arduino Board, Ohms Low, LCD (liquid Cristal display), cable Fault, ADC (Analogue to digital converter), Digital Data.

\section{INTRODUCTION}

In this paper we proposed a blame confinement show for the underground link lines with Arduino. The reason for this paper is to decide the separation from the base station's underground link blame in kilometers. In this task we utilized a basic idea of ohm's low. When a blame happens in the framework the separation situated on fluid gem show (LCD).. Until the most recent decade, links were intended to be set over the head and, at present, there is no underground link that is higher than the past strategy. antagonistic climate conditions, for example, storms, snow, heavy rains and contamination doe no effect on underground lines But when a blame happens in underground lines it is hard to find the blame in underground link. We will locate the precise area of the blame. Presently the world has moved toward becoming digitized in this way, the venture is to identify definite area of the blame in computerized structure.

Underground cabling framework is an increasingly regular practice in numerous urban zones. Despite the fact that the blame happens for reasons unknown, around then, the fix procedure for this specific link is troublesome in view of not knowing the accurate area of the link

Revised Manuscript Received on September 10, 2019.

G.Sasidhar Achari, UG Student, Saveetha School of Engineering, Saveetha University, Chennai, Tamilnadu, India.

(E-mail: sasi.dhar305@gmail.com)

Mohana, Assistant professor, Department of Electronic and Communication Engineering, Saveetha School of Engineering, Saveetha University, Chennai, Tamilnadu, India. breakdown. Blame in link can be characterized in two gatherings.

\section{RELATED WORK}

Tasks moved in Arduino UNO pack to perceive issues from the underground connections. Right when a fault occur in the underground connections, we can find faults through Arduino controller pack. LCD show which demonstrates the insufficiencies in Kilometer . In this endeavor we made faults physically. Connection has various sorts .Every connections has different deterrent which depends on the material used. The estimation of the hindrance is depends on the length of the connection. In here resistance is the principle occupation of the errand .If any deviation occur in the deterrent, the estimation of the voltage will be changed that particular point is called fault. We are find those imperfections.

\section{Types of Faults}

Faults has many types. Frequently occurs the faults are given below.

$$
\begin{array}{ll}
\text { - } & \text { Short Circuit Fault } \\
\text { - } & \text { Open Circuit Fault Fault }
\end{array}
$$

\section{Short Circuit Fault}

A short out fault happens when there is an insurance dissatisfaction between stage conductors or between stage conductor(s) and earth or both. A protection disillusionment results into plan of a short out way that triggers a short out conditions in the circuit .

\section{Open Circuit}

An open-circuit fault occurs if a circuit is impeded by some failure. In case the circuit isn't closed that is called open circuit fault

\section{Earth Fault}

An earth fault is an unplanned contact between an engaged conductor and earth or equipmentframe. The entry method for thefault current is through the setting up structure and any work power or rigging that ends up being a bit of that system. 


\section{LITERATURE SURVEY}

\section{A. Introduction}

A composition overview was coordinated to choose the mechanical as well as current techniques open or used to address this issue for power associations as portrayed in the past segment. The examination is limited to the United States. Licenses recorded over the latest five years; Technical journals (IEEE Transactions on instrumentation and estimations, IEEE Transactions on Circuits and Syste and trades); The arrangements of the dispersion of the imperativeness business; The discontinuous introduction of things in the midst of the latest seven years; And the creator's documentation.

\section{B. Patents}

Of the 25 related licenses found, 5,210,498 number is the most important to this endeavor. Known as the "locator for perceiving underground connections and goofs in that using the ground-breaking electromagnet", a technique is depicted for discovering ground-impelled faults by transmitting a banner on the wire and study the banner Of surface .

\section{Technical Journals}

Pantaloons recommends that a Gaussian estimator, of most prominent repeat, of most outrageous likelihood can choose the trade limit of an immediate structure, of reliable time, of two ports with time delay. The estimator can be used to discover a discontinuity in a connection. The territory of the fault relied upon the rule of Time Domain Reflectometry (TDR). The connection was animated with a heartbeat of brief term. The redesign and the central reflection were tried and the fundamental spooky line $\mathrm{F}$ directed by the snappy Fourier change (FFT) was sent to the estimation count. The causing rate of the connection was essential to choose the last region of the fault. A revamped insightful model portrayed by A bullma'atti proposes the showing of a resistive or capacitive charged line (RC) in light of finding the vague shafts of the trade work. This trade show intends to make it less requesting to complete a PC upheld examination; However, it isn't as exact as other dispersed strategies. Schutt-Aine reported a transient spread examination through non-uniform structures and uniform lines. The examination uses a meaning of dissipating parameters in the time space to develop shut structure computations for current and voltage factors in the line. The method was associated with scaled down scale terminal, outfits and diminished lines. A propelled banner getting ready figuring (DSP) was made to assess the zone of a fault using a line parameter estimation technique. Van Biesen, This method was associated with TDR data examined from a known non-insufficient connection for line parameter arrangement and appeared differently in relation to an accused line to discover the brokenness. The framework requires data of causing speed for precision. It is represented that the strategy enlightens the exactness of $30 \mathrm{~cm}$ using a $20 \mathrm{MHz}-8$-bit sampler.

\section{Murray Bridge loop}

Murray Bridge circle is an augmentation circuit used for constraint of underground or submarine connection inadequacies. it has been used for over 100 years. One finish of the insufficient wire is related by a few resistors to the voltage source. In like manner, a zero identifier is related.

The far edge of the connection is shortcircuited. The scaffold is adjusted by changing the

$\mathrm{RB} 1$ and $\mathrm{RB} 2$ values. $\mathrm{Rz} / \mathrm{Rg}+\mathrm{Ry}=\mathrm{RB} 1 / \mathrm{RB} 2$ This is equal to:

$$
\mathrm{Rz}=(\mathrm{Rg}+\mathrm{Ry}) . \mathrm{RB} 1 / \mathrm{RB} 2
$$

The estimation of $\mathrm{Rx}$ opposition is corresponding to $\mathrm{Lx}$ length, with the goal that the issue point can be determined.

$\mathrm{Lz}=2 \cdot \mathrm{L} \cdot \mathrm{RB} 1 / \mathrm{RB} 1+\mathrm{RB} 2 \mathrm{Where} \mathrm{L}$ is the all out length of the test link - a corresponding Rg esteem.

The system anticipate that there is only a solitary mix-up, low assurance from the security resistance of the connection without damage and connection conductors have a check for uniform length units.

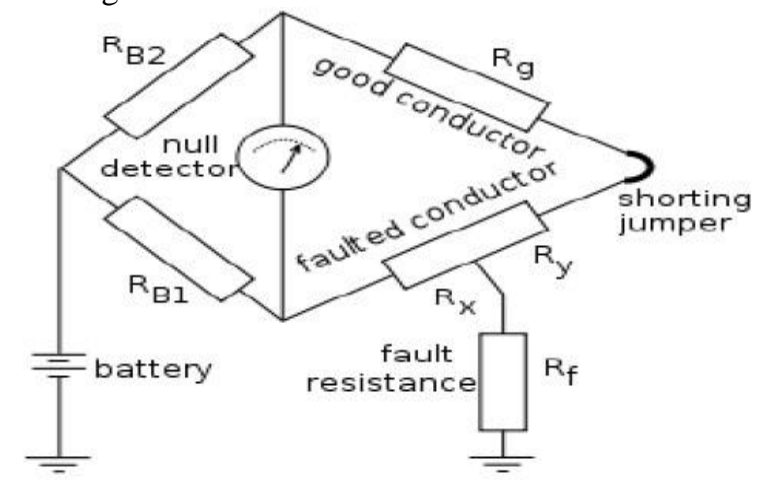

Murray Bridge Loop

Commotion is disturbing effect to human condition that is expanding at such a high rate, that will wrap up being a basic danger to the human creatures. There are different sorts of disarray and now every day's Dolby structure acknowledge veritable work in that. Thusly, we are confronting various issues which are hazardous to individuals. There is no control to fix the sound estimation which is made by utilizing Dolby framework. By and large, the sound estimation is assessed utilizing $\mathrm{dB}$ meter yet one can't control the component of sound. Starting now and into the foreseeable future an Android application is made which control the sound estimation. Also by utilizing RF transmitter and gatherer the sound estimation can be decreased ordinarily to certain low estimation in quiet zone zones.

\section{EXISTING SYSTEM}

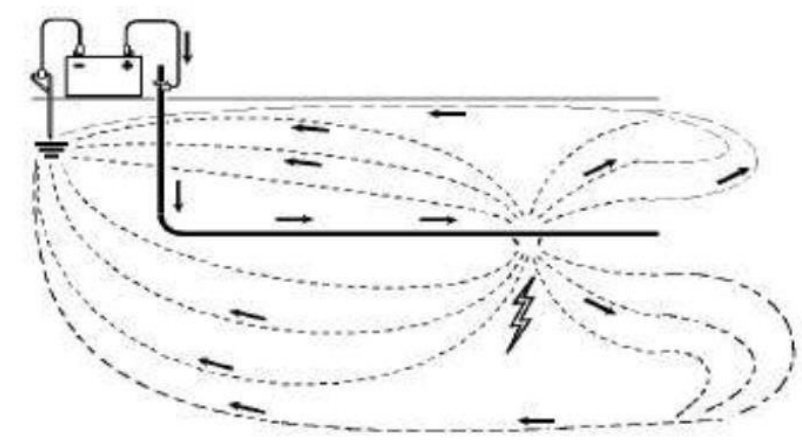

An A-Frame method of finding cable fault location

Published By:

Blue Eyes Intelligence Engineering

\& Sciences Publication 
In A blueprint system, a beat direct current (DC) is imbued into the messed up connection and earth terminal to discover the ground fault. The DC heartbeat will course through the conductor and return by methods for earth from the earth accuse zone back to the ground stake as showed up in Figure 1.The stream of beat DC through the ground will make a little DC voltage. A fragile voltmeter is used to check the significance and direction of the DC voltage in segments of the earth along the connection course. Looking at the eventual outcomes of the assessing voltage along the course, the zone of the fault in the connection can be pinpointed A-Frame is an exact system yet it isn't the fastest one, since the director needs to walk around the length of the connection from the transmitter to the ground fault. This procedure may stand up to an issue if the landing DC finds some less requesting path back to the earth stake of transmitter instead of returning through the ground. In case the ground is sandy, cleared which gives high hindrance and in this manner, less current travels through the ground. Everything considered, the voltmeter fails to evaluate the voltage and accuse area ends up entrapped.

\section{PROPOSED SYSTEM \& RESULTS}

Underground accuse discoverer oversees finding of exact accuse zone from the base station itself. Connections have some resistance. We are essentially focusing that hindrance. Resistance can change with respect to the length of the connection. In case the length of the connection is augmentation, the estimation of the resistance will similarly increase. If any deviation occurs in the impediment regard, we will call that is accuse point and finding that spot through arduino advancement. That accuse point is addresses the standard of detachment (kilometer) from the base station. This regard appeared by grandstand unit.

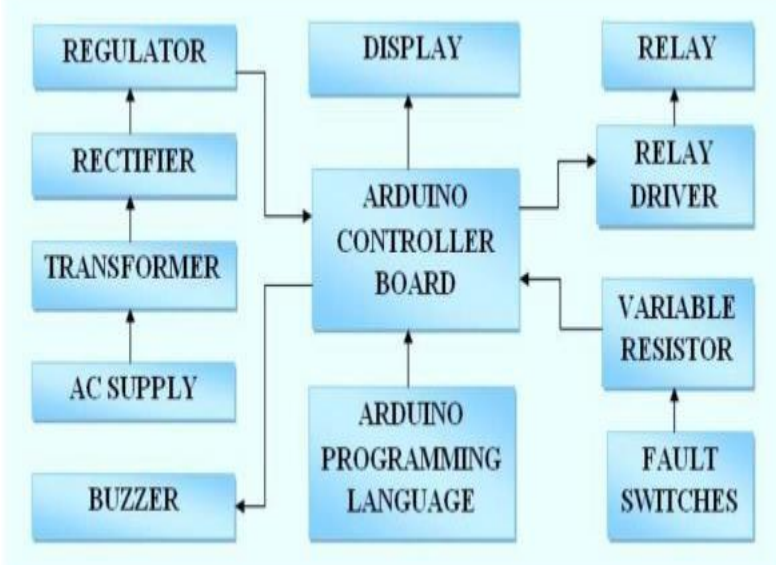

\section{WORKING}

Commonly people have been using business voltage $(230 \mathrm{~V})$.This voltage is adventure down through development down transformer. Transformer is an electrical device that trades electrical imperativeness between in any event two circuits through electromag neticinduction.. Generally, transformers are usedto addition or decreasing the voltages of trading stream in electric power applications. These adventure down voltage goes to rectifier unit Rectifier is just an electronic contraption which used to change over an AC supply into DC supply. This endeavor we were using length rectifier.12V AC supply is changes over into $12 \mathrm{~V}$ DC supply. These voltage moves to the controller unit. Controller is an electrical contraption which is used to keep up a reliable voltage. Here we were using two voltage controller. Explicitly voltage controller 7812 and voltage controller 7805.7812 voltage controller keeps up the $12 \mathrm{~V}$ DC supply. These voltage is adequate to work hand-off unit and 7805 voltage controller keeps up the $5 \mathrm{~V}$ DC supply. These voltage is used to manage the Arduino unit. We moved the program in the unit. Program was created if any fault occur in the connection, immediately will open the exchange terminal and isolate that messed up line in a manner of speaking. Rest of various lines works normally. By and by a days embedded system changed metorically. Arduino is the pushed variation of embedded structure. These Arduino has adequate sorts yet we picked Arduino UNO. These Arduino UNO serves to develope many impelled variation of Arduino UNO makes straightforward condition .it successfully to get various contraptions using consecutive port. Next we move the hand-off. Move is just an electrical contraption here which went about as a switchif any fault occur in the line, will isolate the line using hand-off. The connector of the exchange moves from commonly close direct to the routinely open conducet .we viably find the fault and to isolate the accuse line. Show unit is partner the Arduino pack which is used to where the fault occurs and to demonstrate to itself.

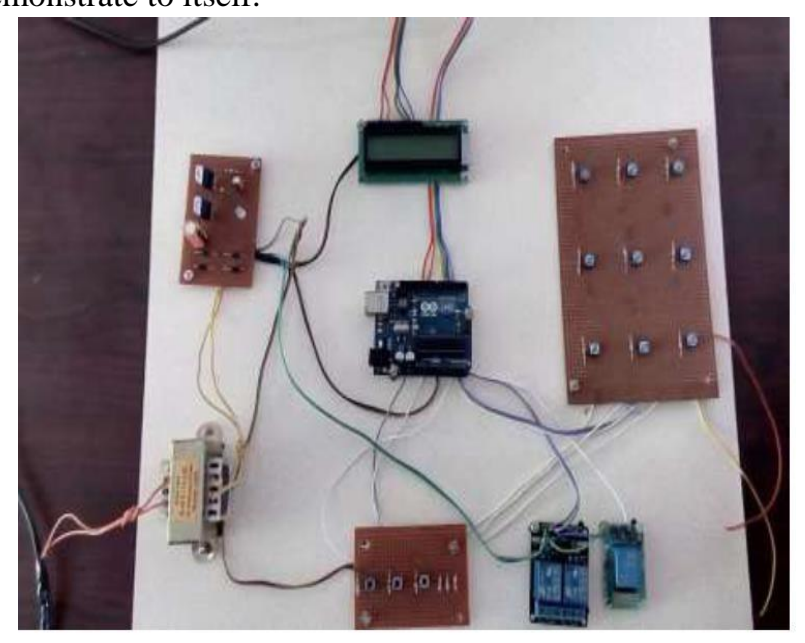

Working Hardware Module

\section{ADVANTAGES AND LIMITATIONS}

\section{A. Advantages}

1. Low Maintains of task

2. Improved open wellbeing.

3. Less utilization of intensity

4. Easy to deal with

\section{B. Limitations}

1. The Arduino and other part require 5V DC Supply..

2. Relay requires $12 \mathrm{~V} \mathrm{dc}$.

3. Sometimes system Problems for country regions may occur. 


\section{CONCLUTION}

It's an irksome errand to perceive the defects in underground connections. By using Arduino controller we can find cautious accuse region. At the point when issues occur in the connection, the feature unit demonstrates the distinct accuse territory that shows which stage is affecteded in the connection and to what degree it's impacted and ringer system is used to make a disturbing sign which is helpful to individuals. Chime system make a disturbing sound banner, once if the fault occur in the underground connection .

\section{REFERENCES}

1. Raghu Raja Kalia, Preeti Abrol, 'Design and implementation of wireless live wire fault detector and protection inremote areas',IEEE,(2014),vol. 97,No.17

2. Touaibia.I, Azzag.E, Narjes.O,'Presentation of HVA faults in SONELGAZ underground network and methods of faults diagnostic and faults location',IEEE,(2014).

3. Pooja.P.S, Lekshmi.M,'Fault detection technique to pinpoint incipient fault for Underground cables, IEEE(2015),vol.3 .

4. Dhekale.P.M,Bhise.S.S,'Underground Cable Fault Distance Locator', IJIER,(2015),Vol.2...

5. Darvhankar.G.S,Gharpande.A.S,Bhope.S.D,Meshr am.A.S,Bobad.A,'Study of 3-ph Underground Cable Fault Locator Using Acoustic',SJIF,(2015),Vol.

6. "Detection of Incipient Faults in Distribution Underground Cables", IEEE Transactions on Power Delivery, Tarlochan S. Sidhu, ZhihanXu, Vol. 25, NO. 3, JULY 2010 